\title{
O ENSINO JURÍDICO NO BRASIL
}

\section{THE LEGAL EDUCATION IN BRAZIL}

Neire Cristina Carvalho Rodrigues ${ }^{1}$ Antonio Carlos Victor Amaral ${ }^{2}$ Vanessa de Lima Andrade ${ }^{3}$

Resumo: $O$ artigo enfoca a questão do ensino jurídico no Brasil, tendo como marco inicial a colonização deste país e a partir daí o incremento que o Direito de fato teve com o passar do tempo. O estudo adequa dessa forma, uma historicidade a respeito desse ensino, sua expansão até a atualidade, e como está atualmente o ensino jurídico no Brasil. O presente artigo será desenvolvido com um conciso histórico do ensino jurídico no Brasil. Após, será apresentado o modelo de ensino dogmático ainda dominante nos dias de hoje e as novas legislações que tentam reverter este quadro. E, por fim, serão apresentados alguns caminhos que podem ser trilhados para se alcançar um ensino que forme profissionais habilitados para garantir a efetividade do Direito na conjuntura social.

Palavras chave: Graduação em Direito. Dogmática. Ensino Jurídico.

Abstract: The article focuses on the issue of legal teaching in Brazil, having as an inicial mark the colonization of this country and, from there, the increament that the Law really had over the time. The study thus adapt a historicity about this teaching, its expansion to the present and how the legal teaching is currently in Brazil. This article will be developed with a concise historical history of legal education in Brazil. Afterwards, it will be presented the model of dogmatic teaching still dominant today and the new legislation that tries to reverse this situation. And, finally, some paths will be presented that can be traced to reach an education that will train professionals qualified to guarantee the effectiveness of Law in the social conjuncture. Keywords: Graduation in Law. Dogmatic. Legal Teaching.

Key words: Graduation in Law. Dogmatic. Legal Teaching.

\section{INTRODUÇÃO}

Delinear o intróito do ensino jurídico brasileiro deve, essencialmente, passar pelo desenvolvimento do Estado brasileiro, ou melhor, como se deu o surgimento e, sobretudo a construção de um país chamado Brasil. De modo óbvio não podemos considerar o nascimento do Estado brasileiro em 1500 com a chegada agressiva das embarcações portuguesas. Não nos cabe aqui, contudo, o exame de tais conjunturas históricas, mas sim, de considerações a respeito de como tais circunstâncias afetaram a questão do ensino jurídico brasileiro.
Milhares de pessoas no Brasil têm interesse extremo pela carreira jurídica. Nos últimos anos foram criados vários cursos jurídicos no país, que oferecem mais vagas aos interessados pela área. No entanto, o célere alargamento do número de cursos de Direito suscita, conseqüentemente, a formação em massa de operadores jurídicos, que saem das instituições de ensino superior, na maior parte dos casos, despreparados para encarar o mercado de trabalho e as novas demandas impostas pela sociedade.

A popularização faz com que a quantidade domine sobre a qualidade do ensino.

\footnotetext{
${ }^{1}$ Mestre em Direito Pela Instituição Toledo de Ensino, especialista em Docência Universitária e em Gestão Estratégica em Educação, e graduada em Direito. cristinaerien@hotmail.com

${ }^{2}$ Doutor em História da Ciência pela PUC/SP, mestre em Administração, mestre em Ciências Contábeis e Atuariais e graduado em Administração e Ciências Contábeis. antoniocvamaral@hotmail.com

${ }^{3}$ Especialista em Direito Constitucional pela Faculdade de Direito Damásio de Jesus direito@fortium.com.br
} 
Deste modo, eterniza-se no panorama nacional um modelo de curso superado, focado somente no dogmatismo normativista, que faz com que os acadêmicos apenas reproduzam o conhecimento, sem novidades na produção de saberes.

Com a finalidade de suplantar o denominado colapso do ensino do Direito, o governo brasileiro instituiu algumas legislações que objetivam aprimorar a qualidade deste ensino. Assim, o presente trabalho tem como desígnio analisar as propostas destas leis, bem como sugerir os plausíveis caminhos que podem ser seguidos para que os cursos de Direito afiancem um ensino efetivamente de qualidade.

O desenvolvimento histórico do ensino do Direito no Brasil pode ser dividido em três fases distintas, ligadas às mudanças na adoção de modelos de Estado. A primeira fase teve início na ampliação do paradigma liberal no Brasil do Império. A segunda fase teve inicio na República Nova e finalizou na era dos governos autoritários. Já a terceira teve início com a promulgação da Constituição Federal de 1988, com o advento da Portaria no 1.886/94 do MEC e com a tendência à adoção do modelo de Estado Neoliberal pelos Governos a partir da década de 1990, na qual nos encontramos no momento.

Inicia-se o presente artigo com um conciso histórico do ensino jurídico no Brasil. Posteriormente, será apresentado o modelo de ensino dogmático ainda dominante e as novas legislações que tentam reverter este quadro. E, finalmente, serão apresentados alguns caminhos que podem ser trilhados para se alcançar um ensino que forme profissionais com senso crítico e aptos à garantir a efetividade do Direito na conjuntura social.

\section{EVOLUÇÃO HISTÓRICA DO ENSINO JURÍDICO}

Não haviam instituições de ensino superior no Brasil no período colonial. A formação acadêmica era realizada Europa, os candidatos dirigiam-se quase sempre para Portugal, na Universidade de Coimbra, sendo que apenas os brasileiros endinheirados tinham a capacidade de se mudar para a Metrópole para estudar.

Até o ano de 1822, o Brasil era colônia de Portugal e Portugal nunca se preocupou em constituir escolas superiores em suas colônias, isso porque, a política de Portugal sempre foi no sentido de não admitir a fundação de escolas superiores no Ultramar. Os movimentos para o surgimento do Ensino Jurídico no Brasil tiveram início pela Faculdade de Direito de Coimbra, onde os estudantes brasileiros disputavam vagas. Isso persistiu, prioritariamente, até a sanção da Carta de lei de 11 de agosto de 1827, que instituiu os cursos de Direito em São Paulo e Olinda. O primeiro projeto de criação e implantação do Curso de Direito no Brasil foi apresentado durante a Assembléia Constituinte de 1823.

Somente em 1827, com a instalação da família real no Brasil, é que foram criados os primeiros cursos jurídicos no Brasil, nas cidades de Olinda e São Paulo. Em 11 de agosto de 1827, é criado no Brasil o Curso de Ciências Jurídicas e Sociais da Academia de São Paulo e o Curso de Ciências Jurídicas e Sociais em Olinda, que mais 
tarde foi transferido para Recife. Entretanto, ditos cursos também estavam voltados a atender a fina flor da sociedade brasileira, já que a função basilar era formar o fausto burocrático do Império, exigindo-se do estudante na entrada nestas faculdades os seguintes requisitos: apresentação da certidão de nascimento, mais de quinze anos de idade, ser aprovado em testes de língua francesa, retórica, gramática latina, filosofia e geometria. Cumpre ressaltar que a implantação dos cursos jurídicos do Brasil ocorreu em um contexto marcado especialmente pela recente proclamação da Independência (1822). De igual modo ressalta-se que a criação das Faculdades de Direito no Brasil seguiu a tendência européia, estas instituições de ensino eram dirigidas pelas classes dominantes, com escopo, inicial, de aprimorar os quadros administrativos do Estado. (SANTOS, 2002, p.36.)

Desta forma, os servidores letrados compunham o aparato burocrático do Estado, fator que levou ao aparecimento de práticas de corrupção e nepotismo dentro deste quadro. O governo utilizava do poder de nomeação dos magistrados para garantir seus interesses. Assim, os juízes deixavam "(...) de apreciar conflitos de sua competência (impessoalidade, neutralidade) para entrar numa prática 'antijudiciária', em que só contava o atendimento ao partido aliado e aos chefes no interior." (WOLKMER, 2007, p.118-119)

Neste diapasão, obter a graduação em um curso de Direito significava não apenas participar da administração estatal, mas também ser reconhecido socialmente, ou melhor, ascender a um status social superior. Isso era muito expressivo numa sociedade que ainda mantinha o regime escravocrata em que os trabalhos manuais eram menosprezados. Deste modo, nas faculdades jurídicas brasileiras pregava-se o "(...) ideário de uma camada profissional comprometida com o projeto burguêsindividualista, projeto assentado na liberdade, na segurança e na propriedade" (WOLKMER, 2007, p.125)

Com o surgimento da República, sob a intensa influência das aspirações positivistas, mostrou-se necessário a criação de novas instituições de ensino. Os Estados e, até mesmo particulares, tinham a consentimento para estabelecer instituições de ensino superior, desde que os requisitos ao ingresso fossem iguais aos das faculdades sob a administração do governo central.

Depois do advento do Estado Novo e da Constituição de 1937 muitas foram as reformas feitas na educação brasileira como, por exemplo, a Lei de Diretrizes e Bases da Educação, em 1961, que criou o Conselho Federal de Educação, que passou a ter um papel basilar no desenvolvimento de uma política educacional no Brasil. Entretanto, ditas reformas, apesar de salutares, não suscitaram resultados muito expressivos, no que tange a qualidade do ensino jurídico no país. As reformas não atenderam as pretensões de intelectuais que ambicionavam um ensino jurídico que estivesse interligado com as questões sociais, ou seja, um ensino que não se reduzisse ao tecnicismo.

A partir da década de 1960, com o Governo Militar as instituições de ensino superior transformaram-se em meras transmissoras de 
ideais pré-concebidos. Foi determinado de maneira imposta, um sistema educacional dissociado da realidade sócio-econômica do país. Durante a década de 70 , muitos juristas passaram a debater acerca da crise do ensino do Direito, procurando assinalar as razões das deficiências.

No final do século XX, numa conjuntura anterior a redemocratização do Brasil, verificou-se forte "(...) mobilização social, na qual vários juristas revelaram-se sensíveis aos princípios democráticos e capazes de perceber as inconsistências da ordem jurídica e as contradições da sociedade capitalista." (BEZERRA, 2006) Assim, muitos bacharéis que não pertenciam aos grupos familiares tradicionais, procuraram novos caminhos ao Direito, no que se alude a sua composição e seus usos.

\section{Com o advento da Constituição}

Federal de 1988 houve espaço democrático para mudanças expressivas no ensino jurídico. Diversos direitos e garantias haviam sido inseridos no ordenamento jurídico brasileiro pela nova constituição e toda essa marcha cidadã comportaria novidades nos cursos de Direito. Assim, novas legislações passaram a existir e, neste contexto, depois de muitos debates realizados entre profissionais do Direito, da Ordem dos Advogados do Brasil (OAB) e do Ministério da Educação, foi editada a Portaria no 1.886/94 do MEC. Essa Portaria ofereceu diretrizes curriculares, que deveriam ser observadas no ensino do Direito.

As mudanças e as inovações trazidas ela Portaria 1.886/94, robustecidas por uma política estatal de inspeção e avaliação cíclica das IES, refletiram de modo positivo no panorama educacional do Direito. O intervencionismo estatal chegara com meio século de retardamento no ensino jurídico. Essa portaria apresentou muitas mudanças nos cursos de Direito, mudanças estruturais, inovações qualitativas que nunca antes exigidas.

Depois, a legislação passou por algumas modificações, sendo editada a Resolução n ${ }^{\circ}$ 09/2004 do Conselho Nacional de Educação (CNE), que representa as Diretrizes Curriculares para o curso de Direito, que representou uma tentativa de reestruturar algumas diretrizes, como por exemplo, tornar essencial os conteúdos de Antropologia, Ciências Políticas, Economia, Ética, Filosofia, História, Psicologia e Sociologia na grade dos cursos. Mas, ainda que pese tenham ocorrido todas essas alterações e mudanças na legislação, em relação à sala de aula não existiu avanço significativo. $\mathrm{Na}$ verdade, é na sala de aula que se confere o desafio de transformar o ensino jurídico no Brasil, porque ela continua a exprimir e reproduzir a ideologia liberal e uma pedagogia tradicional.

Hoje há os que conjecturam a criação de novas Diretrizes curriculares para o curso de Direito, o que de toda forma, já não era sem tempo. Necessitamos que o currículo fosse revisto e mais que isso modernizado.

\section{O ENSINO JURÍDICO CONTEMPORNEO}

A conjuntura hodierna do ensino jurídico, assinalada pela má qualidade, é provocada, sobretudo, pela massificação da entrada nas universidades; pelo despreparo dos alunos oriundos de um ensino médio deficitário; 
pela desvalorização das relativas profissões, o que enseja o direcionamento para o sistema universitário não por aptidão, mas como passagem para uma participação qualificada no mercado de trabalho, dentre outros fatores menos aviltantes.

A maior inquietação do meio acadêmico atual é com a instituição de técnicas e perspectivas voltadas para a eficácia, o que vem impondo ao Direito uma visão tecnicista, de maneira a afastá-lo cada vez mais da realidade social, cultural e política que o circula. Hoje em dia, sem embargo das tentativas de mudanças por parte do governo, o ensino jurídico ainda pauta-se no dogmatismo, na descontextualização com a realidade vivenciada e na unidisciplinariedade, o que afeta sobremaneira o estudo do Direito enquanto ciência social.

O que muito se tem notado nas instituições que ofertam o curso de Direito, é que o ensino eterniza o dogmatismo, ou seja, verdades inquestionáveis e restritas à letra da lei. Um ensino que unicamente reproduz conhecimentos e não os renova. O ensino jurídico brasileiro encontra-se em meio a um colapso didático-pedagógico, isso porque a maior parte dos professores de Direito, ainda que lecione com base na simples transferência dos conteúdos, ambiciona e acredita que curso de Direito poderia ser melhor, e merecia ser diferente.

Vendo a questão de forma pontual denota-se que o simples conhecimento do ordenamento jurídico já não é satisfatório para o sucesso no processo de ensino e aprendizagem. Existe uma descontextualização entre o conhecimento jurídico e a realidade social. Os alunos ficam cada vez mais afastados das demandas sociais as quais o Direito tem capacidade de cooperar. Assim, os acadêmicos de Direito adquirem uma visão reducionista do funcionamento da sociedade, à medida que apresentam-se, na maioria das vezes, como meros receptores de informações que estão positivadas pelo Estado.

É cediço de todos que a mera exposição de conteúdos suscita, no máximo, a reprodução do conhecimento que existe até então; o aluno não desenvolve a consciência reflexiva cogente para pensar sobre os temas discutidos, estando à margem de uma formação humanística, política e social mais concreta.

No entanto, de acordo com Paulo Freire, ensinar não se resume a transmissão destas informações. Tal tarefa exige apreensão da realidade, pois:

"A memorização mecânica do perfil do objeto não é aprendizado verdadeiro do objeto ou do conteúdo. Neste caso, o aprendiz funciona muito mais como paciente da transferência do objeto ou do conteúdo do que como sujeito crítico, epistemologicamente curioso, que constrói o conhecimento do objeto ou participa de sua construção". Deste modo é necessário incentivar à produção, e fazer o educando buscar as respostas dentro das demandas que o cercam.

A confusão comum que se faz entre Direito com lei, impõe ao operador jurídico somente decorar e manejar as regras impostas, isentando-o de posturas críticas. No entanto, tal padrão de ensino e aprendizagem já não corresponde as novas demandas colocadas pelo mercado de trabalho, que tem exigido, cada vez 
mais, dos profissionais da área, habilidades para lidar com novas situações e "novos direitos" que brotam com a rápida transformação social.

O ensino jurídico, da mesma forma que outros ramos do saber, têm o anseio da autonomia. $\mathrm{O}$ docente tem determinado conhecimento como alguma coisa acabada, pronta, hierarquizada e compactado sob a forma de uma disciplina. Nestas disciplinas, dificilmente abre-se espaços de contato com outros conhecimentos, como História, Filosofia, Sociologia, Antropologia, Política, entre outros saberes, que são menosprezados e desvalorizados no curso de Direito. Desta forma, o conhecimento jurídico, "(...) já profundamente afetado pelas técnicas dogmáticas de construção de sentido, no tocante aos níveis de abstração com as quais lida, necessariamente, vê-se, progressiva e perigosamente, distanciado do substrato social que o circunda." (SANTOS, 2002, p.70)

Para se alcançar uma postura autônoma e para entender os "novos direitos" que nascem com as mudanças sociais o ensino jurídico carece de mudanças essenciais. As legislações que trazem as diretrizes aos projetos políticos pedagógicos aos cursos jurídicos são importantes ao rompimento com dogmatismo e com o ensino pautado em decorar tão somente, mas não basta apresentá-las, pois é preciso cobrar a efetivação das mesmas no cotidiano das salas de aula.

O curso de Direito não deve exclusivamente formar um profissional da área jurídica, mas de igual forma preparar o individuo para encarar as circunstâncias cotidianas e, para isso "(...) é preciso cultivar a sensibilidade e a humildade que nos tornam capazes de compreender a dimensão dos problemas que nos cercam e admitir que a maior parte deles foge à solução jurídica." (COSTA, 2009, p.15)

Muito se debate a respeito destas deficiências do ensino jurídico, que, incontestavelmente, encontra-se em um contexto maior - o de falência do ensino no país como um todo, que se desdobra desde o ensino básico ao ensino superior. Mas, mostra-se necessário mudanças cogentes neste padrão de ensino, a fim de que o Direito possa evoluir com as novas necessidades sociais, ou seja, que se mantenha "(...) a efetividade do Direito em si, sua integridade, seu compromisso com a justiça e com a pacificação social, enfim sua missão de transformador da sociedade na direção de uma convivência mais harmônica para todos." (SANTOS, 2002, p.97-98)

\section{ALTERNATIVAS AO ENSINO DO DIREITO}

Para assinalar alternativas de melhorias para o ensino do Direito, é indispensável, basicamente, identificar suas falhas, de modo a tratá-las de forma prática e direta. Em primeira mão, tem-se a metodologia usada desde o início até os dias atuais: “aulas expositivas", este padrão de ensino faz com que o estudante receba de forma passiva o que o professor expõe, e somente leia os textos e decore as leis.

O Brasil passou por intensas mudanças nos últimos tempos, mudanças políticas, sociais, econômicas e culturais que, por conseguinte, alteraram o perfil do ordenamento 
jurídico. Nada obstante, o padrão de ensino e aprendizagem jurídico ainda apresenta-se estagnado, ou seja, ineficaz às novas demandas que são colocadas aos profissionais do Direito.

Segundo Álvaro Melo Filho (2004, p.

74), é importante destacar

(...) que o curso talvez seja o mais fácil para se fazer e o mais difícil para se vencer, daí porque é preciso ter cuidado para que o diploma de bacharel em Direito a ser obtido não se transforme apenas num enfeite ornado com uma moldura e pregado na parede, dado que, atualmente, no campo profissional do Direito, há pouquíssimos lugares para os bons e muitos lugares para os ótimos. Por isso é preciso refletir sobre o ensino e a aprendizagens jurídicas, sobretudo diante da proliferação quantitativa e 'macdonização' dos cursos jurídicos (...).

Assim, a reformulação do ensino do Direito tem de buscar, basicamente:

a) o rompimento com o positivismo normativista;

b) a superação da concepção de que só é profissional do direito aquele que exerce atividade forense;

c) a negação da auto-suficiência ao

direito;

d) a implosão da compreensão de educação restrita à sala de aula;

e) a necessidade de um profissional com formação integral (interdisciplinar, teórica, crítica, dogmática e prática.

É necessário em primazia, rescindir as travas existentes com o padrão predominante do positivismo jurídico, pois o procedimento de ensino deve promover o raciocínio e garantir a autonomia intelectual dos discentes, com a finalidade de impedir que os mesmos sejam contaminados pelo legalismo tão somente.

O ensino pautado apenas na repetição de conteúdos está superado. O mercado de trabalho estabelece que o profissional da área jurídica tenha ciência e consiga encarar os "novos direitos" que brotam na esfera social, haja vista que as questões cotidianas não são definidas apenas com deduções. Os conhecimentos dogmáticos precisam ter significado e aplicação. Deste modo, o que se busca é um ensino do Direito que dê aos alunos conhecer novas tendências e novos caminhos.

Em um segundo plano, deve-se estimular a criticidade, através de debates e utilizando-se de tecnologias aplicadas à educação.

O estudante de Direito tem que ter um pensamento reflexivo, deve estar ligado às novas demandas sociais, não podendo ser apenas um espectador e um repetidor de informações.

Assim, o mundo do Direito não admite pensamento único e engessado, a forma de ensinar o Direito deve ser mais criativa, mais dinâmica, colocando o aluno para ser o sujeito da relação e tentado lhe dar autonomia. O método de ensino deve ser agregador e deve afiançar o diálogo num espaço educacional solidário, em que educadores e educandos possam construir conhecimento de forma cooperada. A sala de aula deve ser um espaço de troca, onde se possa exercer a liberdade intelectual.

Em terceiro lugar, uma questão a ser discutida com seriedade se refere à avaliação de aprendizagem, a avaliação não pode se resumir apenas em aplicar provas ou fazer destas umas 
punição para os educandos. A avaliação tem que espelhar o processo real de aprendizagem.

Em quarto e não menos importante, é salutar aproximar os alunos à realidade, ou melhor, desenvolver atividades de campo, atividades práticas a fim de comprovar aos mesmos que o Direito pode ser um instrumento transformador da realidade. Ditas atividades não podem ter apenas o viés assistencialista, mas sim emancipatório.

Em quinto lugar é necessário se atentar que ensino jurídico no Brasil necessita de procedimentos didáticos capazes de preparar o aluno para as prováveis circunstâncias com as quais irá se deparar quando em exercício da atividade profissional, por essa razão a formação pedagógica do docente é essencial. O docente necessita ser melhor preparado para poder preparar.

Por derradeiro, devem os cursos de Direito incitar a iniciação científica, estimular a pesquisa, é necessário que o aluno de Direito comece a valorizar a pesquisa como produção intelectual que sirva a alguma coisa, que essa produção se preste a ajudar alguém. Por se tratar de atividade complexa, que demanda tempo e dedicação daquele que a desenvolve, é necessário que o professor seja preparado para essa atividade, pois este professor será o orientador desse aluno. Assim, as instituições devem ofertar um curso de metodologia de pesquisa a professores e alunos, com a finalidade de que esses agentes possam entender os métodos de pesquisa envolvidos na investigação científica.

\section{CONSIDERAÇÕES FINAIS}

Sem dúvida alguma, as legislações que versam sobre o ensino jurídico no país, apresentam ou querem apresentar alguma solução para que o quadro de colapso seja ultrapassado. Entretanto, muitas instituições de ensino superior insistem em manter projetos pedagógicos superados, incoerentes com a realidade em que vivemos.

Os projetos pedagógicos devem ser reformulados para atender as novas demandas sociais, é cogente pensar novas metodologias aplicadas aos educadores e aos educandos.

Assim, o anseio deste estudo foi proporcionar algumas soluções ao ensino jurídico e apontar que as transformações devem partir de ações das instituições de ensino, juntamente com docentes e discentes com o objetivo de se alcançar uma educação atenta às necessidades sociais, políticas, econômicas e culturais do Brasil.

Quando se fala em educação jurídica, é necessário se falar em pensar toda estrutura do ensino jurídico. Não tem como modificar a composição hoje posta, se não se revolucionar o próprio conhecimento predominante sobre o direito. Há uma precisão de se romper com todo o sistema de ensino do direito; meras reformas não solucionarão esse problema. É forçoso que seja definido uma nova ciência jurídica harmônica à realidade social, que procure indicar novos desígnios para um ensino do direito ideal para o alcance de uma sociedade melhor e mais justa. Desse modo, o ensino jurídico deixará de ser uma mera transferência de conteúdos para se tornar uma atividade que possibilite os alunos a produzirem os próprios conceitos e serem comprometidos com o aprimoramento 
democrático do Estado brasileiro e a modernização de nossa sociedade. É necessário que se faça o ajustamento dos conteúdos às requisições do século XXI, e que dos estudantes não se espere mais a capacidade de decorar leis e institutos, mas sim a desenvoltura de instituir um raciocínio jurídico que lhes permita interpretá-los de forma apropriada, almejando tirar deles seu íntimo atrelamento com os fatos sociais e com a realidade de nosso tempo.

\section{REFERÊNCIAS}

BARRETO, Vicente. Sete notas sobre o ensino jurídico. In: UNIVERSIDADE DE BRASÍLIA. Encontros da UnB. Ensino Jurídico. Brasília: UnB, 1978 - 1979.

BASTOS, Aurélio Wander. O ensino jurídico no Brasil. 2. ed. RJ: Lumen Juris, 2000.

BEZERRA, Francisco Otávio de Miranda. Ensino jurídico numa perspectiva cidadã: interação social e políticas públicas. 2006. 236 f. Dissertação de Mestrado (Especialização em Políticas Públicas) - Universidade Estadual do Ceará, Fortaleza, 2006. Disponível em:

$<$ http://www.politicasuece.com/v6/admin /publicacao/FRANCISCO_OTAVIO_DE_MIR ANDA_BEZERRA.pdf $>$. Acesso em: 24 nov. 2010.

BITTAR, Eduardo C.B. Direito e ensino jurídico. Legislação educacional. São Paulo: Atlas, 2001.

BORTOLON, Mariana Cavarra. A necessidade de uma formação efetiva no ensino do Direito. In: FRANCISCHETTO, Gilsilene Passon (Org.). Ensino jurídico e pedagodia: em busca de novos saberes. 1.ed. Curitiba: Editora CRV, 2010.

BRASIL. Conselho Nacional de educação. Resolução no 09/2004. Disponível em: <http://www.ufv.br/seg/diretrizes/dir.pdf>. Acesso em: 14 de maio de 2017.

COSTA, Renata P. Carvalho; FRANCISCHETTO, Gilsilene Passon. Ensino jurídico "versus" positivismo jurídico: para uma visão plural do direito. Panóptica, ano 2, n. 16, jul. 2009. Disponível em:

<http://www.panoptica.org/2009juloutpdf/01_2 009_jul_out_1_26pp.pdf $>$. Acesso em: 20 de abril de 2017.

FILHO, Álvaro Melo. Desafios atuais do ensino e aprendizagem do direito. Revista da Jurídica da Fic - Faculdade Integrada do Ceará, Fortaleza, v.3, n.4, 2004. Disponível em: $<$ http://www.fic.br/v4/downloads/pdf/REVIS TA_JURIDICA_4.pdf $>$. Acesso em: 14 de maio de 2017.

FREIRE, Paulo - Pedagogia da autonomia: Saberes necessários à prática educativa. 25.ed. São Paulo: Paz e Terra, 1996.

FRANCISCHETTO, Gilsilene Passon. Em busca de novos saberes: uma aproximação entre o ensino jurídico e pedagogia. In: . Ensino jurídico e pedagodia: em busca de novos saberes. 1.ed. Curitiba: Editora CRV, 2010.

RIBEIRO, Wanderley. Da formação à deformação: crise no ensino jurídico. In: XVII Encontro Preparatório para o Congresso Nacional do CONPEDI, 2008, Salvador. Anais do CONPEDI. Disponível em:

$<$ http://www.conpedi.org.br/manaus/arqu ivos/anais/salvador/nelson_wanderley_ribeiro_m eira.pdf>. Acesso em: 14 de maio de 2017

ROCHA, José Vinicius de Souza. Ensino Jurídico transformador. Revista de Ciências Jurídicas e Sociais da UNIPAR, Umuarama, v. 10, no 1, jan./jun. 2007.

SANTOS, André Luiz Lopes dos. Ensino jurídico: uma abordagem político-educacional. Campinas: Edicamp, 2002.

SOUZA, Sabrine Pierobon de. O cotidiano do ensino e aprendizagem do direito numa instituição de ensino superior. 2006. $161 \mathrm{f}$. Dissertação de Mestrado (Especialização em 
Educação) - Pontifícia Universidade Católica de Campinas, Campinas, 2006. Disponível em:

<http://www.bibliotecadigital.puc-

campinas.edu.br/tde_busca/arquivo.php?codArq uivo $=110>$. Acesso em: 02 abril. 2017.
WOLKMER, Antonio Carlos. História do Direito no Brasil. Rio de Janeiro: Forense, 2007. 